Article

\title{
Analysis of Very High Spatial Resolution Images for Automatic Shoreline Extraction and Satellite-Derived Bathymetry Mapping ${ }^{\dagger}$
}

\author{
Giovanni Randazzo 1,2,3, Giovanni Barreca ${ }^{1,3}$, Maria Cascio ${ }^{1}$, Antonio Crupi 1,3, \\ Marco Fontana ${ }^{1}$, Francesco Gregorio ${ }^{1}$, Stefania Lanza ${ }^{1,3}$ and Anselme Muzirafuti ${ }^{1, *(D)}$ \\ 1 Interreg Italia-Malta-Progetto: Pocket Beach Management \& Remote Surveillance System, \\ University of Messina, Via F. Stagno d'Alcontres, 31-98166 Messina, Italy; grandazzo@unime.it (G.R.); \\ giovanni.barreca83@gmail.com (G.B.); maria.cascio86@gmail.com (M.C.); antoniocrupi5@hotmail.it (A.C.); \\ marco.fontana92@yahoo.it (M.F.); gregoriofrancesco92@gmail.com (F.G.); lanzas@unime.it (S.L.) \\ 2 Dipartimento di Scienze Matematiche e Informatiche, Scienze Fisiche e Scienze della Terra, \\ Università degli Studi di Messina, Via F. Stagno d'Alcontres, 31-98166 Messina, Italy \\ 3 GeoloGIS s.r.l. Spin Off, Via F. Stagno d'Alcontres, 31-98166 Messina, Italy \\ * Correspondence: a.muzirafuti@edu.umi.ac.ma; Tel.: +39-3312976306 \\ $+\quad$ This paper is an extended version of our paper published in 2019 IMEKO TC-19 International Workshop on \\ Metrology for the Sea; Muzirafuti, A.; Crupi, A.; Lanza, S.; Barreca, G.; Randazzo, G. Shallow water \\ bathymetry by satellite image: A case study on the coast of San Vito Lo Capo Peninsula, Northwestern Sicily, \\ Italy. In Proceedings of the 2019 IMEKO TC-19 International Workshop on Metrology for the Sea, Genoa, \\ Italy, 3-5 October 2019.
}

Received: 25 March 2020; Accepted: 5 May 2020; Published: 8 May 2020

check for updates

\begin{abstract}
The amount of Earth observation images available to the public has been the main source of information, helping governments and decision-makers tackling the current world's most pressing global challenge. However, a number of highly skilled and qualified personnel are still needed to fill the gap and help turn these data into intelligence. In addition, the accuracy of this intelligence relies on the quality of these images in times of temporal, spatial, and spectral resolution. For the purpose of contributing to the global effort aiming at monitoring natural and anthropic processes affecting coastal areas, we proposed a framework for image processing to extract the shoreline and the shallow water depth on GeoEye-1 satellite image and orthomosaic image acquired by an unmanned aerial vehicle (UAV) on the coast of San Vito Lo Capo, with image preprocessing steps involving orthorectification, atmospheric correction, pan sharpening, and binary imaging for water and non-water pixels analysis. Binary imaging analysis step was followed by automatic instantaneous shoreline extraction on a digital image and satellite-derived bathymetry (SDB) mapping on GeoEye-1 water pixels. The extraction of instantaneous shoreline was conducted automatically in ENVI software using a raster to vector (R2V) algorithm, whereas the SDB was computed in ArcGIS software using a log-band ratio method applied on the satellite image and available field data for calibration and vertical referencing. The results obtained from these very high spatial resolution images demonstrated the ability of remote sensing techniques in providing information where techniques using traditional methods present some limitations, especially due to their inability to map hard-to-reach areas and very dynamic near shoreline waters. We noticed that for the period of 5 years, the shoreline of San Vito Lo Capo sand beach migrated about $15 \mathrm{~m}$ inland, indicating the high dynamism of this coastal area. The bathymetric information obtained on the GeoEye-1 satellite image provided water depth until 10 m deep with $\mathrm{R}^{2}=0.753$. In this paper, we presented cost-effective and practical methods for automatic shoreline extraction and bathymetric mapping of shallow water, which can be adopted for the management and the monitoring of coastal areas.
\end{abstract}


Keywords: remote sensing; GeoEye-1; unmanned aerial vehicle (UAV); image processing; satellite-derived bathymetry (SDB); binary imaging analysis; coastal erosion; pocket beach; San Vito Lo Capo; climate change

\section{Introduction}

Very high resolution (VHR) images acquired by means of Earth observation satellites or unmanned aerial vehicles (UAV) contain an important amount of Earth surface's information, which can be used to tackle the world's most pressing global challenges, such as climate change, population growth, and natural resource depletion. Satellite images with different spatial resolutions have been particularly used to evaluate coastline morphological change evolution [1], as well as morphological modeling of coastline [2]. Multi-temporal shorelines extracted on VHR satellite images [3] have allowed the reconstruction of shoreline evolution and, eventually, the assessment of coastal erosion process. Advancement both in sensors and algorithms capacity has facilitated onshore [4], as well as offshore [5], studies performed using satellite images. Proxy-remote sensing using UAV allows obtaining VHR data with very detailed information, especially used in agriculture [6] or for other environment studies [7-9].

In coastal areas, heavily affected by the impact of climate change [10], VHR images are used for accurate mapping of shoreline evolution [11] and for predicting and determining the coastal storm impacts [12]. Although these VHR images are the main source of information for our past, present, and future Earth system, their acquisition requires sufficient financial means. Their analysis and processing [13] also require highly skilled and qualified personnel in order to extract end-user intelligence. In the current paper, we presented a framework of image analysis for automatic extraction of shoreline both from GeoEye-1 satellite image and orthomosaic image acquired by an unmanned aerial vehicle (UAV), as well as shallow water depth extracted on GeoEye-1 satellite image. The methodology, applied on the coast of San Vito Lo Capo-a large Pocket Beach in the north-west Sicily (Italy), included binary images creation of water and non-water pixels on which shorelines were automatically extracted using ENVI software via raster to vector (R2V) algorithm. The binary image obtained from GeoEye-1 was later used for water masking of blue and green bands, which were used for satellite-derived bathymetry (SDB) mapping in conjunction with available in-situ data. Whereas the past remote sensing studies conducted using R2V approach were land-based studies [14] or for identification of shoreline changes using moderate spatial resolution images [15], the current study proposed the application of R2V analysis on VHR images by using only one input near infrared (NIR) band for GeoEye-1 image and red for UAV orthomosaic). Analysis of the GeoEye-1 image was completed by conducting SDB mapping in order to take the full advantage of VHR images application for on land, as well as on offshore, studies.

Mapping shallow water bathymetry in coastal and near-shore areas is of greatest interest to explorers, hydrographers, and scientists who want to have a better understanding of this highly dynamic environment [16-18]. Water depth information is essential for many applications, especially for coastal environment impact assessment and protection, nautical charting, construction planning and leisure, hydrodynamic modeling, and environmental exploration $[19,20]$. With ongoing climate change, temporal monitoring of shallow water depth can reveal geomorphological and land cover changes occurring in coastal areas, which are important parameters for hydrodynamic and wave modeling [19]. For example, the position of the shoreline is influenced by the level of the sea, and knowledge of water depth can help identify the location of the sand beach and sediment deposits and also improve coastal erosion studies [21]. In underwater archeology, water depth information is used for mission planning and, therefore, facilitates the discovery of lost objects and artifacts [22]. In seismic survey exploration, water depth information constitutes an important component for seabed determination and improves natural resources' mapping. 
Usually, ocean, sea, and lake bathymetry studies are conducted using traditional methods, such as multi-beam echo sounder and single beam echo sounder (SBES), fixed on ships and vessels [23,24], and Lidar fixed on aircraft $[25,26]$. These methods need onsite deployment, exploration license permits, and their equipment are very expensive [27]. They are highly precise but time-consuming when studying large areas. In addition, they present some challenges when they are used in very near-shore due to area inaccessibility and hidden seabed rocks, which can halt the passage of ships and vessels [28]. For Lidar, the main challenge is in its high cost, which makes it unsuitable for small projects; in addition, administrative procedures needed for flight authorization can also complicate the planned missions.

To overcome these issues, SDB is presented as an answer for shallow water bathymetry mapping in order to complete the gap left by traditional methods, as well as to update previously available bathymetric data [29]. Since the 1970s, different SDB approaches have been used to extract depth water information using multispectral satellite images [30]; however, advances in satellite sensors and the development of new algorithms are making this technology more attractive, and it is now being used in many sectors and industries, such as oil and gas, coastal engineering [31], aquaculture, and ports and infrastructures.

Recently, SDB has been adopted as a monitoring technique by different companies, such as EOMAP and TCARTA, offering commercial services related to shallow water bathymetry and seabed surveys [32,33]. These companies provide bathymetry information to different organizations but also to different national hydrographic offices, especially for updating and improving nautical charts. As an example, in October 2015, the BA 2066 chart of Southern Antigua was published by the UK Hydrographic office [34].

With intense activities and high levels of interaction occurring in coastal areas, the shoreline and SDB mappings are regarded as important tools for the monitoring and surveillance of anthropic and natural changes. Application of these tools on the pocket beach of San Vito Lo Capo-presented as the case study - constituted a typical remote surveillance methodology, which can be adopted for small and naturally protected beaches in order to access the impact of changing climate at local as well as regional scales. We intended to explore their ability to identify shoreline reference features, used for shoreline extraction, and eventually coastline analysis. On the other hand, we wanted to determine if SDB could provide very near shoreline sediment positions involved in coastal erosion process occurring in this highly dynamic environment.

\section{Materials and Methods}

\subsection{Area of Study}

San Vito Lo Capo is located in northwestern Sicily in the northernmost sector of the karstic peninsula (Figure 1). This area has important archeological and touristic sites and is considered as the second touristic destination, in Sicily, after Taormina. San Vito Lo Capo hosts a large sand beach with gradual deep clear water and a harbor facility. The area was selected because of its constant sand shifting of the beach, as testified by the local population, with drifting sand from East to West, depositing into the harbor; this process affects both maritime transport by reducing the space for boat maneuvering and other stakeholders because of the loss of valuable space.

On the pocket beach of San Vito Lo Capo, significant changes in the beach morphology are restricted to severe weather episodes when wave-related processes are enhanced [35]. Moreover, both the biogenic carbonate sediments are provided by the communities living in the seagrass meadows (i.e., Posidonia oceanica). The relict sediments also play an important role in the natural supply of sediments to the beaches. This supply is of even greater importance in areas where there is a lack of sediment from rivers; hence, relict sediments may maintain the beach in a state of equilibrium [36].

The seafloor of the San Vito bay is colonized by extended meadows of the seagrass, which grow on rocky outcrops from depths of 10-20 m and continue along the whole coast of the peninsula (Figure 1). 
During the year, prevailing winds are mainly from the first quadrant, sometimes in the form of severe storms, especially during winter; this generates a sediment drift from East to West, which cannot be equilibrated by spring waves, which, in the past, before the construction of the harbor, maintained the equilibrium of the shoreline, pushing the sediments eastward. Based on shoreline and water depth evolutions, it is possible to determine regions occupied by accumulated and lost sediments [37] and help improve the functioning of the harbor and possibly contribute to regional economic development.

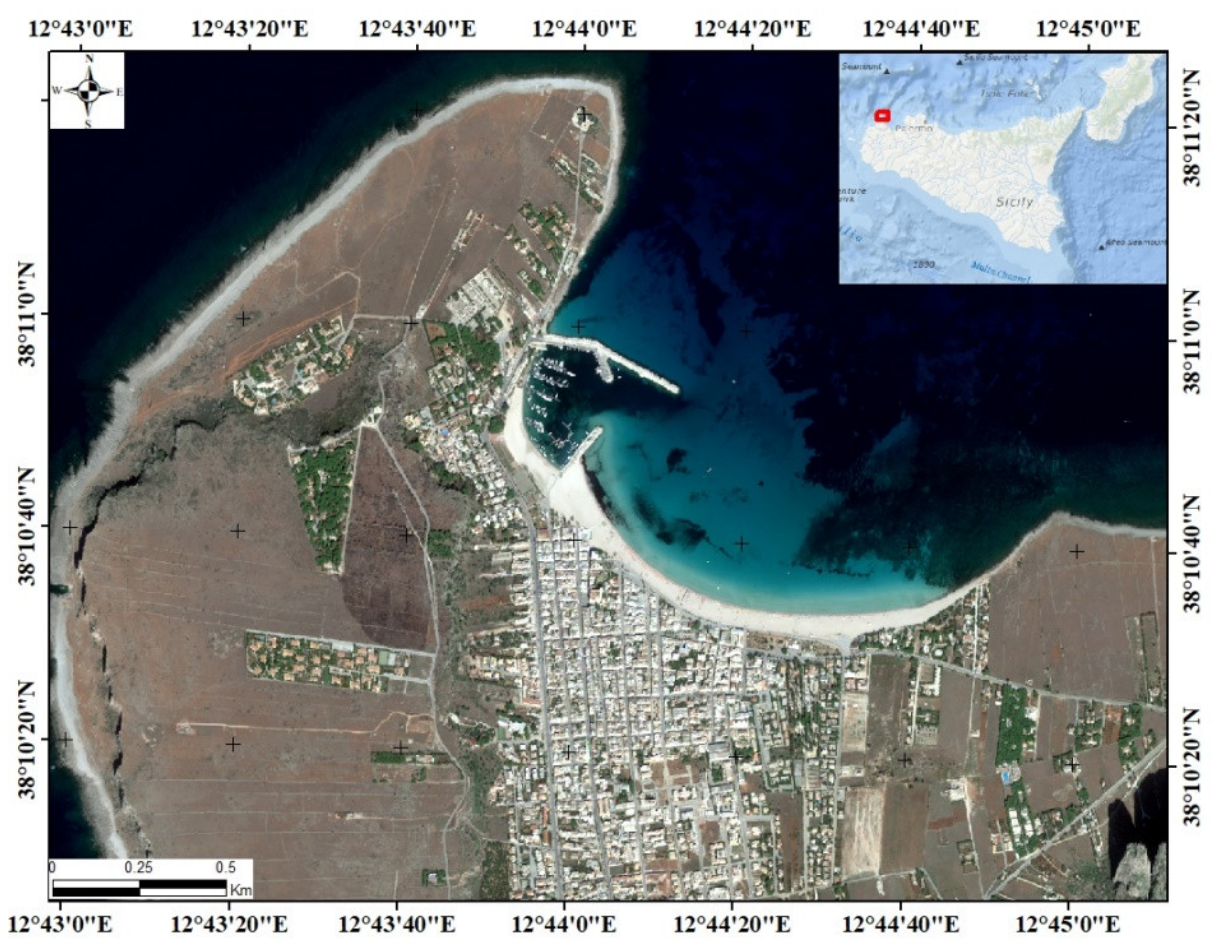

Figure 1. Map, indicating the location of the coast of the San Vito Lo Capo peninsula. Note the presence of large sand beach, harbor, and the city of San Vito Lo Capo (C) GeoEye-1 satellite image acquired on 18 October 2014).

\subsection{Data Used}

The satellite image analyzed in this study was acquired on 18 October 2014 on the coast of San Vito Lo Capo by GeoEye-1, a satellite of DigitalGlobe Company. The main characteristics of this image are presented in Table 1 . The image had four multispectral bands (blue, green, red, and NIR) with a spatial resolution of $2 \mathrm{~m}$. It also had a panchromatic band acquired with $50 \mathrm{~cm}$. Automatic shoreline extraction was performed using the NIR band, while SDB mapping was conducted using blue and green bands. For SDB mapping, these bands were analyzed in conjunction with in-situ bathymetry acquired in December 2013 (Table 2).

UAV orthomosaic image used in the current study was a result of preprocessing images acquired using DJI Mavic pro 2 aircraft during the fieldwork conducted on 28 May 2019 on the coast of San Vito Lo Capo. Table 3 presents the main characteristics and aircraft setting parameters for UAV images acquisition. After fieldwork acquisition, these images were preprocessed in Pix4Dmapper software. During preprocessing, a dataset of 1691 images was calibrated with a median of 8862.13 matches per calibrated image. In addition, 54 ground control points (GCPs) were acquired using a global positioning system (GPS) real-time kinematic (RTK) rover. These GCPs were used to enhance UAV orthomosaic georeferencing precision, which resulted in a root mean square error (RMSE) of $0.098 \mathrm{~m}$. 
Table 1. GeoEye-1 satellite image used.

\begin{tabular}{|c|c|c|c|c|}
\hline Image Type & Panchromatic & & \multicolumn{2}{|l|}{ Multispectral } \\
\hline Spatial resolution & $0.5 \mathrm{~m}$ & & \multirow{2}{*}{\multicolumn{2}{|c|}{$\begin{array}{l}2 \mathrm{~m} \\
450-520 \mathrm{~nm} \text { for the blue band } \\
520-600 \mathrm{~nm} \text { for the green band } \\
625-695 \mathrm{~nm} \text { for the red band } \\
760-900 \mathrm{~nm} \text { for the NIR band }\end{array}$}} \\
\hline Spectral resolution & $450-900 \mathrm{~nm}$ & & & \\
\hline \multirow[t]{4}{*}{ Image calibration parameter } & Gain $\mathrm{mw} /\left(\mathrm{cm}^{2} \times \mathrm{nm} \times \mathrm{sr}\right)$ & Offset & $\begin{array}{c}\text { Gain } \mu \mathrm{w} /\left(\mathrm{cm}^{2} \times \mathrm{nm} \times \mathrm{sr}\right) \\
0.14865 \text { for blue band }\end{array}$ & $\begin{array}{c}\text { Offset } \\
0\end{array}$ \\
\hline & & & 0.10135 for green band & 0 \\
\hline & 0.08715 & 0 & 0.16194003 for red band & 0 \\
\hline & & & 0.05705 for NIR band & 0 \\
\hline Off-Nadir imaging & \multicolumn{4}{|c|}{26 degrees } \\
\hline Coordinate system & \multicolumn{4}{|c|}{ WGS 1984 UTM Zone 33N } \\
\hline Cloud cover & \multicolumn{4}{|c|}{0} \\
\hline
\end{tabular}

Table 2. In-situ data acquired using Single Beam Echo Sounder Garmin 550C.

\begin{tabular}{ccc}
\hline $\begin{array}{c}\text { Positional Instrument } \\
\text { Coordinate System } \\
\text { Navigation Software }\end{array}$ & DGPS Garmin CSX 60 signal differential WAAS EGNOA \\
& Datum: Roma 1940 (Monte Mario), Projection: ( Gauss Boaga ) \\
Qinsy QPS 8.1.0 & \multicolumn{2}{c}{ Qins } \\
Tide Station & National mareographic network_station of Palermo \\
& Date: $07-11-2013$ & Date: $08-11-2013$ \\
& High value: $0.225 \mathrm{~m}$ & High value: $0.2 \mathrm{~m}$ \\
Lathymetric Map Scale & Low value: $-0.024 \mathrm{~m}$ & \\
\hline
\end{tabular}

Table 3. Aircraft sensing parameters and main characteristics of UAV orthomosaic.

\begin{tabular}{cc}
\hline Sensing Parameters & DJI Mavic pro 2 Aircraft \\
\hline Sensor type & Camera Hasselblad L1D-20c-20 Mega pix \\
Spatial resolution & $1.58 \mathrm{~cm}$ \\
Spectral resolution/number of bands & 3 bands RGB \\
Radiometric resolution & $24 \mathrm{BIT}$ \\
Flight altitude & $60 \mathrm{~m}$ \\
Flight duration & 20 minutes \\
Total area covered & $0.62 \mathrm{~km}^{2}$ \\
Flight speed & $75 \%$ frontal-75\% side \\
Sensing type & $5.2 \mathrm{~m} / \mathrm{s}$ \\
Forward and sideward overlap sensing & automatic \\
Number of people mobilized & 3 \\
Off-Nadir imaging & 28 May 2019, 11: 00 UTC \\
Coordinate system & 0 degree \\
Image type & GGS84 UTM zone 33 N \\
Number of flights & GeoTIFF \\
Global navigation & 3 \\
satellite system (GNSS) & GPS+GLONASS \\
\hline
\end{tabular}

\subsection{Methodology}

In this study, two VHR images were analyzed: (1) GeoEye-1 satellite image was preprocessed in order to convert top-of-atmosphere (TOA) spectral radiance into water reflectance via atmospheric correction process. The atmospherically corrected image was used to extract shoreline position and later to compute SBD, and (2) UAV orthomosaic image was only analyzed in order to extract the shoreline position, which was later used to analyze coastline parameters. 
Figure 2 shows the steps adopted in order to extend the preliminary results obtained by analyzing the GeoEye-1satellite image for SDB mapping [38] and by integrating UAV orthomosaic for shoreline position mapping.

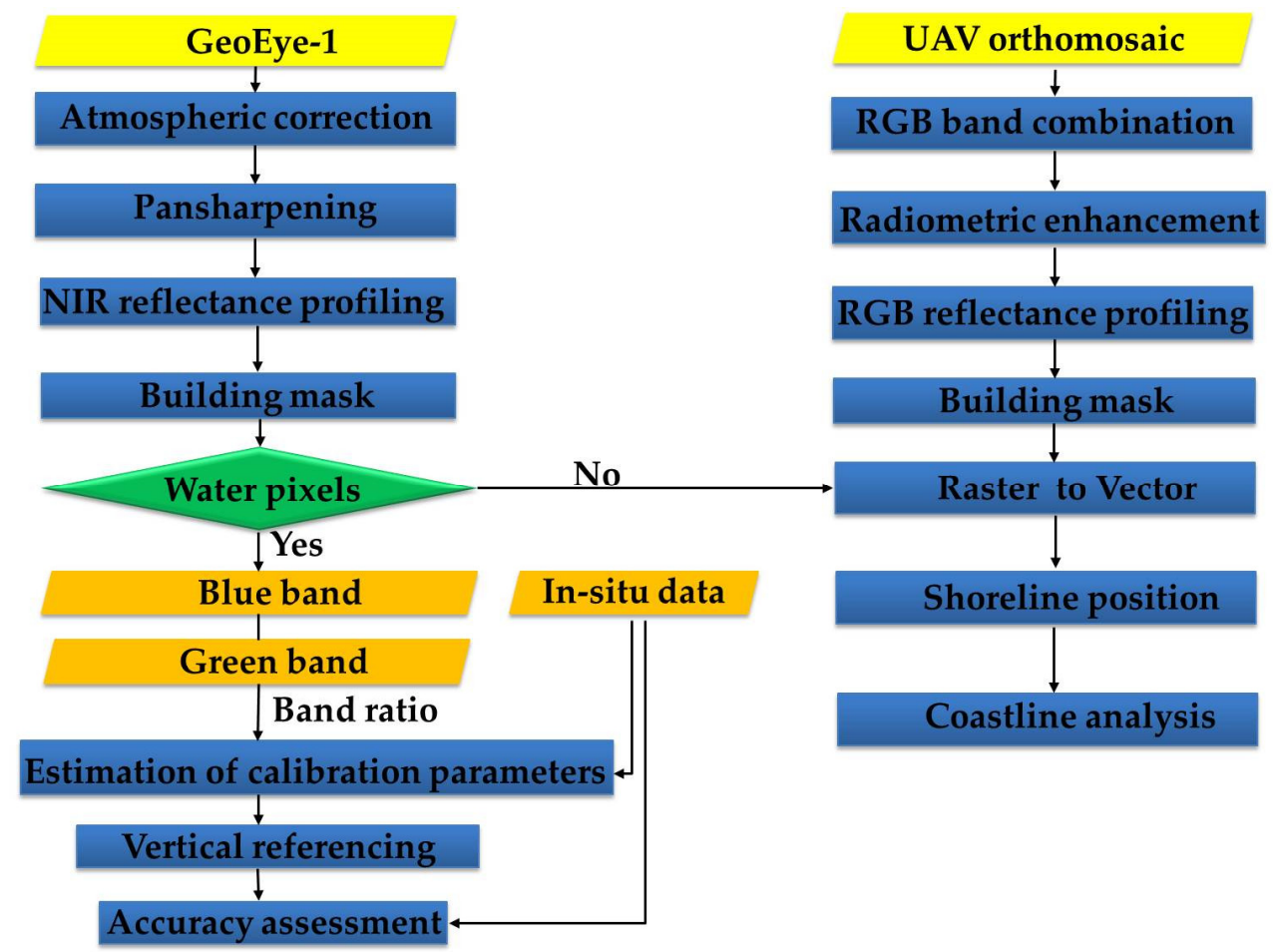

Figure 2. Flowchart, indicating different steps adopted for satellite-derived bathymetry (SDB) mapping and shoreline extraction.

During the acquisition of satellite image, top-of-atmosphere (TOA) reflectance (Equation (1)) saved over water varies with absorption $(\alpha)$, backscattering $(\beta)$, and water reflectance $(\rho)$.

$$
\rho(\mathrm{TOA})=\frac{\pi \times \mathrm{L} \lambda \times \mathrm{d}^{2}}{\operatorname{ESUN} \lambda \times \cos (\theta \mathrm{s})}
$$

where $\rho$ (TOA) is the top-of-atmosphere reflectance, ESUN $\lambda$ is mean solar extra-atmospheric irradiance expressed in $\mathrm{W} \times \mathrm{m}^{-2} \times \mu \mathrm{m}^{-1}$, $\mathrm{d}$ is Earth-sun distance obtained from Julian day acquisition time, $\mathrm{L} \lambda$ represents top-of-atmosphere spectral radiance, and $\theta \mathrm{s}$ is solar zenith angle equal to 90 degrees minus the sun elevation angle at the time of image acquisition in the integration manager database (IMD) files.

This reflectance is a function of water depth $(Z)$ and is expressed as follows:

$$
\rho(\mathrm{TOA})=\mathrm{f}(\mathrm{Z} \alpha, \beta, \rho)
$$

However, this reflectance $\rho$ (TOA) is affected by atmospheric composition, and it has been noted that only less than $1 \%$ of $\rho$ (TOA) contains information about the water [39], thus an atmospheric correction is needed to remove atmospheric noise, which can affect the quality of the image used for water depth estimation. This atmospheric correction was computed via fast line-of-sight atmospheric analysis of hypercube (FLAASH) [40], a tool that is integrated into ENVI and IDL software (v. 5.5). FLAASH is a physics-based atmospheric correction that corrects wavelengths from the visible to near-infrared and shortwave infrared regions by removing absorption $(\alpha)$ and backscattering $(\beta)$ to obtain the water reflectance. The atmospheric correction was followed by the orthorectification process designed for topographic variations correction. In addition, the pan-sharpening process was performed 
in order to enhance spatial resolution from $2 \mathrm{~m}$ to $50 \mathrm{~cm}$. All these processes were computed in ENVI software (v. 5.5).

\subsubsection{Automatic Shoreline Extraction}

In order to automatically extract shoreline on VHR images, binary images were firstly created both from the GeoEye-1 NIR band and UAV orthomosaic red band. The creation of these images was aiming at distinguishing water and non-water pixels in VHR images. Then, each pixel was coded to 1 for water or 0 for non-water. The attribution of these digital numbers was based on threshold reflectance values extracted on the GeoEye-1 NIR band (Figure 3) and UAV orthomosaic red band (Figure 4). Table 4 shows the maximum and minimum reflectance values used for water and land masking.

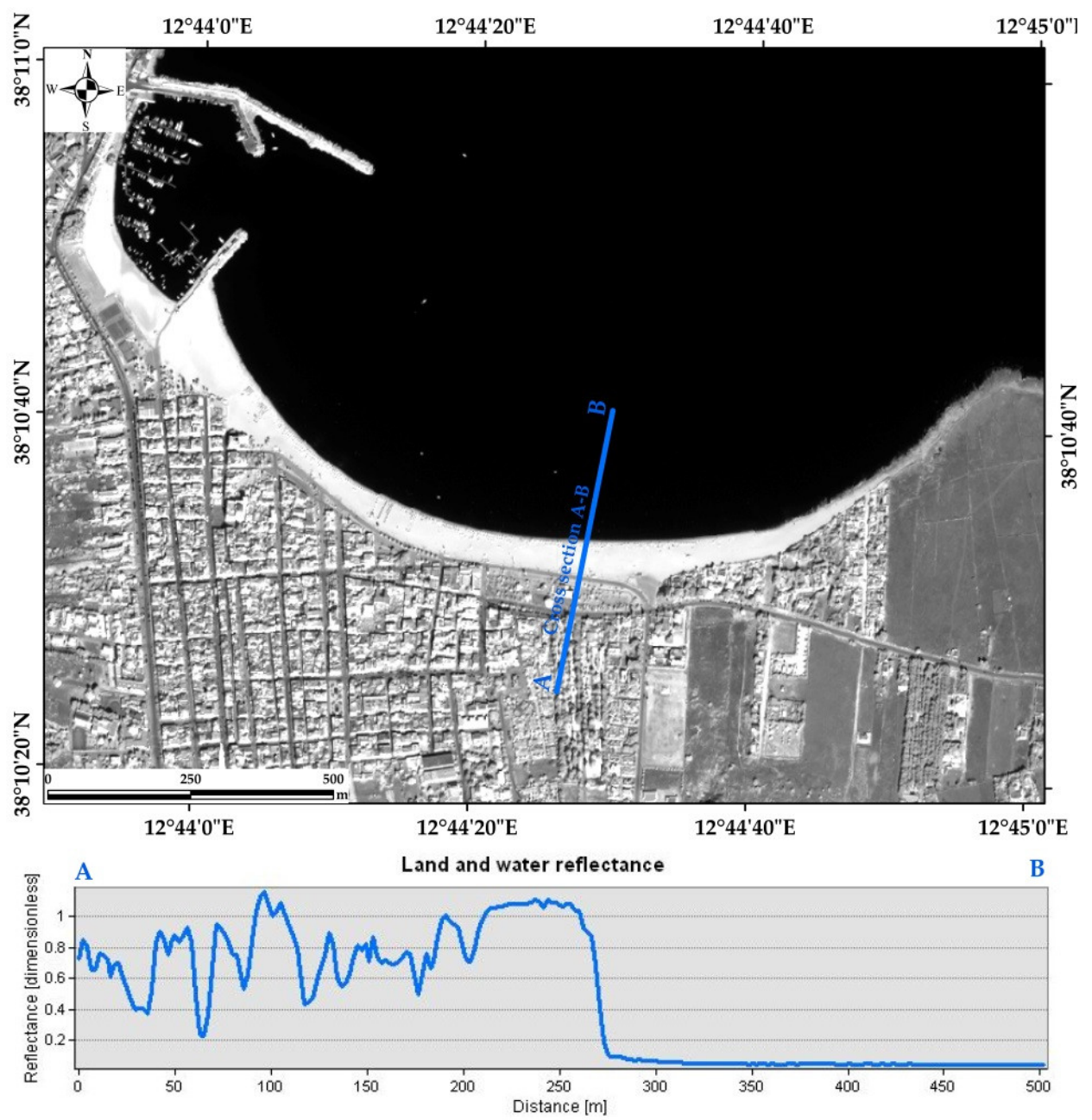

Figure 3. Reflectance thresholding on GeoEye-1 NIR band. The blue line indicates the interpolated line (cross-section A-B) used for land and water reflectance extraction. The blue profile graph indicates the variation of reflectance with low and constant values extracted on water and high and fluctuating values extracted on non-water pixels.

The spectral band of the VHR image could be represented as a matrix with each pixel represented by a reflectance value. This band matrix representation allowed the transformation of the original band into a binary image by applying the masking threshold reflectance values. Figure 5 illustrates an example of the transformation of the original GeoEye-1 NIR band into a binary image by applying threshold reflectance values between land and the water. The image obtained was a binary image composed of two digital numbers-1 for water pixels and 0 for non-water pixels. 


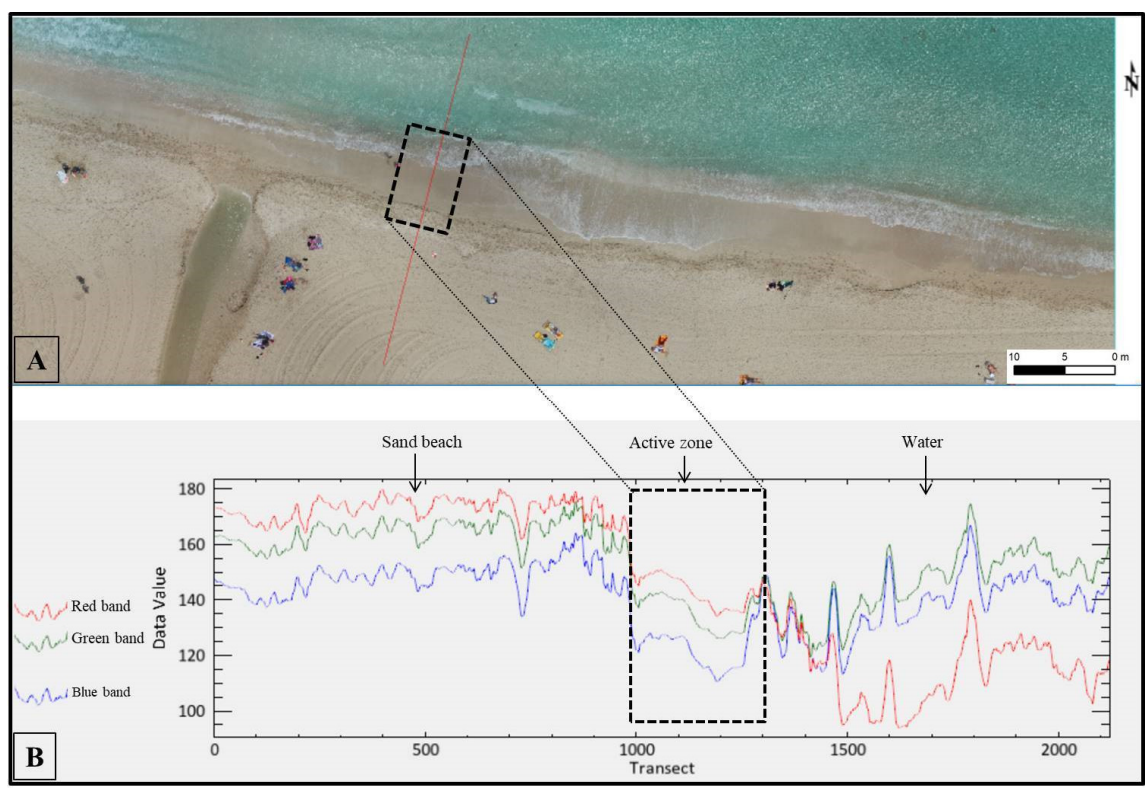

Figure 4. Reflectance thresholding on unmanned aerial vehicle (UAV) orthomosaic image. The very high-resolution three-band-red, green, blue-image (A), indicating areas occupied by a sand beach, active zone (high and low water level), and water. The analysis of reflectance data pixels for each band revealed changes in data values, especially in a red band with high, relatively low, and low values for the sand beach, active zone, and water, respectively.
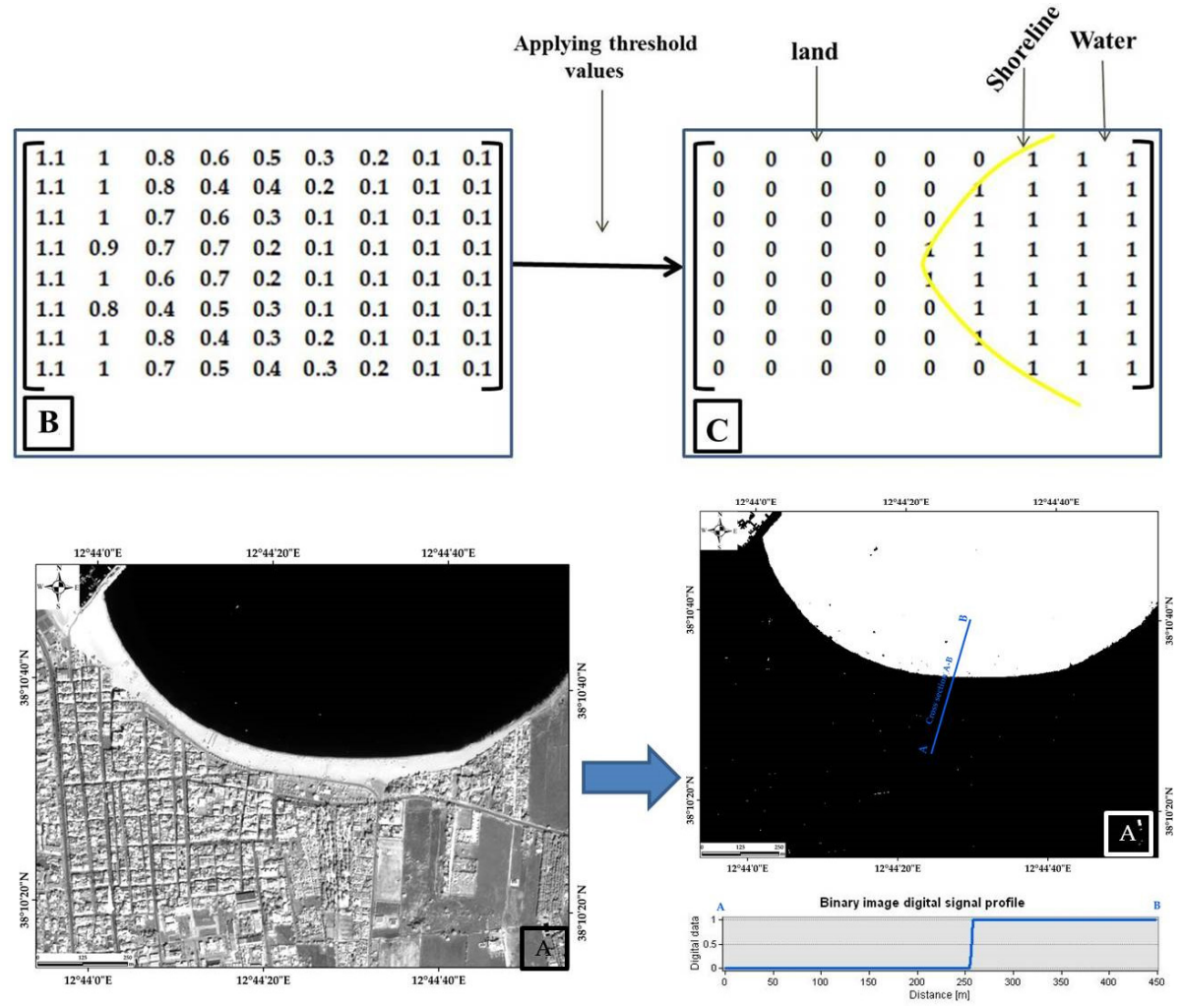

Figure 5. Band matrix representation (B), illustrating original GeoEye-1 NIR band (A) on which threshold reflectance values were applied to build a binary image $\left(\mathbf{A}^{\prime}\right)$. The position of the shoreline can be identified at the intersection of 1 and 0 as represented on matrix representation $(C)$ of a binary image or in the contact of land and water represented in the binary image by zeros and ones, respectively $\left(\mathrm{A}^{\prime}\right)$. The binary image digital signal profile revealed the edge between land and water. This edge was detected by the raster to vector (R2V) algorithm and was used for the vectorization process. 
Table 4. Masking out GeoEye-1 NIR and UAV orthomosaic red band based on threshold reflectance values.

\begin{tabular}{cccc}
\hline \multirow{2}{*}{ Band Features } & \multicolumn{2}{c}{ Masking Threshold } & Definition \\
\cline { 2 - 3 } & GeoEye-1 NIR Band & $\begin{array}{c}\text { UAV Orthomosaic } \\
\text { Red Band }\end{array}$ & \\
\hline Land & $\geq 0.35$ & $\geq 160$ & $\begin{array}{c}\text { Sand beach and built up area } \\
\text { with high values } \\
\text { Water }\end{array}$ \\
\cline { 2 - 3 } & $\leq 0.35$ & $\leq 160$ & Shallow water with low values \\
\hline
\end{tabular}

Secondly, the binary images were transformed into vectors via the R2V algorithm installed in ENVI software. This algorithm was capable of detecting the edge pixels between 1 and 0 (water and land) (Figure 5 $\mathrm{A}^{\prime}$ ) and transform this edge into polyline (shoreline). The process was automatic and could be summarized as follows: (1) detected the edge between water and non-water pixels, (2) established the connectivity between consecutive edges, (3) identified the location of consecutive edges and traced their continuity, (4) exported the polylines with spatial georeference information. Figures 6 and 7 show examples of shorelines extracted on the GeoEye-1 NIR band and UAV orthomosaic red band. Coastline geomorphological analysis conducted, based on the positions of these shorelines, provided information on changes occurred on the coast of San Vito Lo Capo.

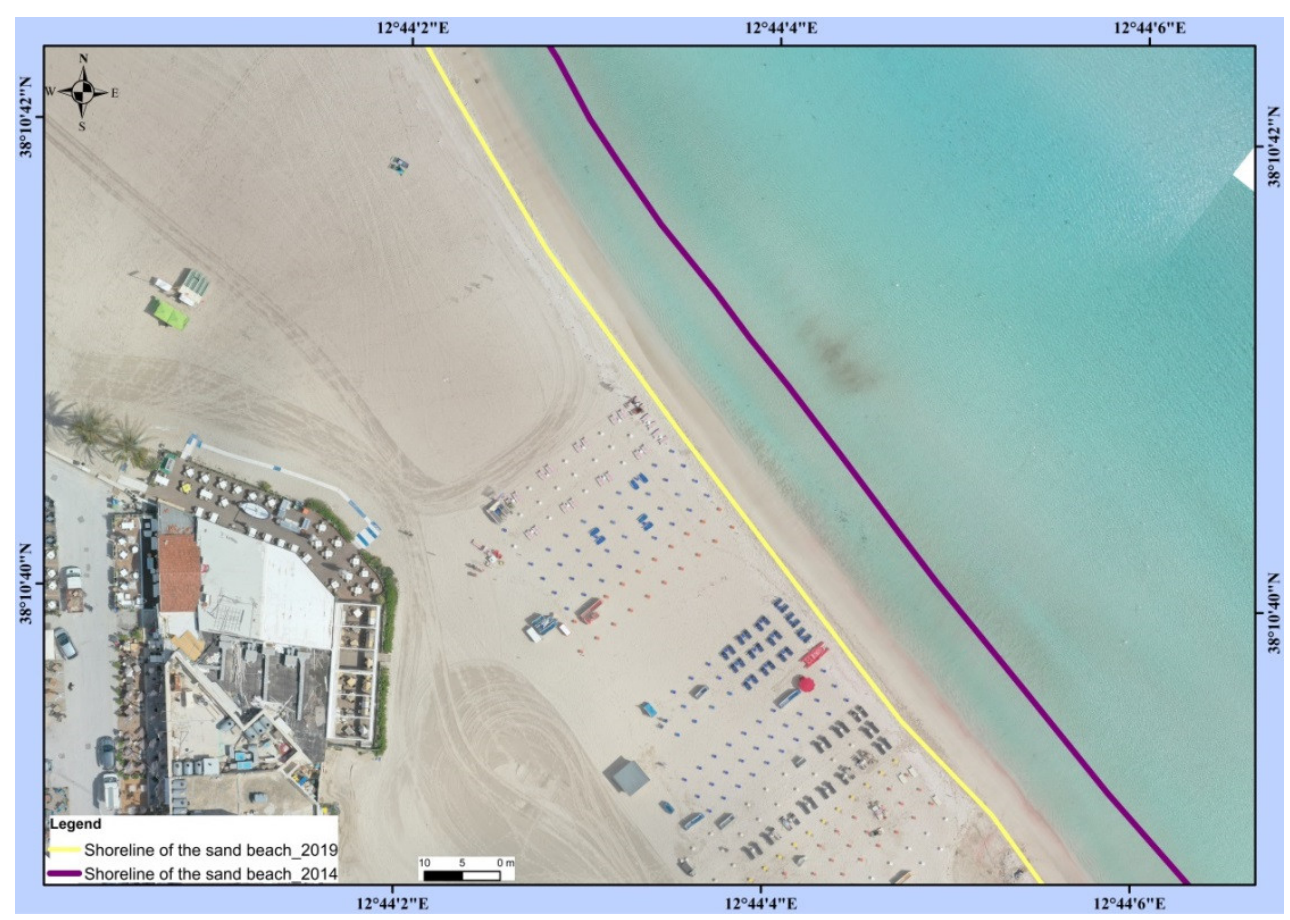

Figure 6. Map of 2019 and 2014 sand beach shorelines positions overlapped on the UAV orthomosaic image acquired on 28 May 2019 on the coast of San Vito Lo Capo. The 2019 shoreline was extracted on UAV orthomosaic, whereas the 2014 shoreline was extracted from the GeoEye-1 satellite image. 


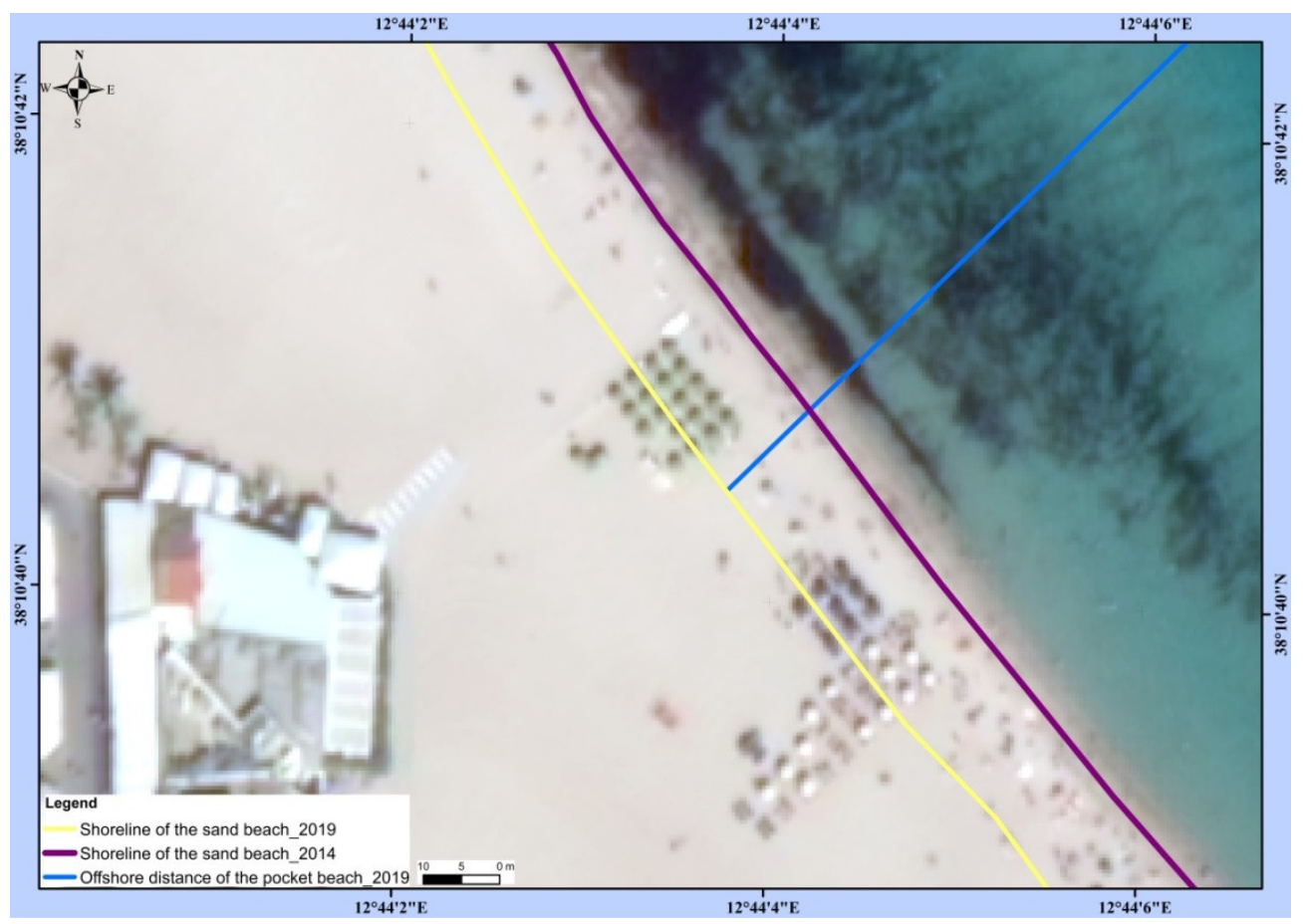

Figure 7. Map of 2019 and 2014 sand beach shorelines positions overlapped on the GeoEye-1 satellite image acquired on 18 October 2014 on the coast of San Vito Lo Capo. Note the offshore distance between 2014 and 2016 shorelines, indicating the migration of $15 \mathrm{~m}$ length of the sand beach.

\subsubsection{Satellite-derived Bathymetry}

In this paper, we used an optical-based approach, a log-band ratio method using empirical calibration parameters suitable for bathymetry estimation, focusing on two spectral bands-green and blue [41]. The third band, near-infrared, was used for land/water masking, while field data were used for calibration and vertical referencing to the local datum.

The log band ratio method was applied only on the GeoEye-1 satellite image, as shown in Figure 2. As the image was acquired in good conditions (Table 2), no sun glint correction [42] was needed to remove sea surface reflection.

Thus, after atmospheric corrections, the shallow water reflectance equation could be defined as it is shown in Equation (3).

$$
R w=\rho_{b} \cdot e^{-2 K Z}
$$

where $\mathrm{Rw}$ is water reflectance, $\rho_{b}$ is bottom reflectance, $\mathrm{Z}$ is the depth of the seabed, e is the logarithmic base, and $2 \mathrm{~K}$ is the (up-welling and down-welling) operational two-way diffuse attenuation coefficient.

Assuming that the area of study has a uniform bottom reflectance and water attenuation, we applied Stumpf et al. [41] equation (Equation (4)) for SDB calculation using two spectral bands in blue and green. The application of this equation minimized the influence of bottom reflectance and water attenuation parameters on the area of study, with respect to water depth variation. It took into account known water depth for calibration and vertical referencing. The method adopted was a log-band ratio method using an empirical iterative solution and attenuation coefficient assumption for bathymetry estimation.

$$
Z=m 1 \frac{\ln (n R w(\lambda i))}{\ln (n R w(\lambda j))}-m 0
$$

where $\mathrm{Z}$ is absolute depth (SDB), $\mathrm{m} 1$ (gradient of the line) is a tunable constant to scale the ratio to the depth, $\mathrm{Rw}$ is water reflectance, $\mathrm{n}$ is fixed value for all areas to ensure the logarithm will be positive and 
the relationship will be linear, $\mathrm{m} 0$ is the offset for the depth of $0 \mathrm{~m}(\mathrm{z}=0)$, the interception with the $\mathrm{Y}$ axis, $\lambda \mathrm{i}=$ band $\mathrm{i}, \lambda \mathrm{j}=$ band $\mathbf{j}$.

The log-band ratio method was computed in ArcGIS software (v. 10.2.2, ESRI) in two main steps: first by extracting relative bathymetry from two bands (blue and green), after applying a low-pass 3-by-3 (kernel size $3 \times 3$ ) filter, and, finally, by conducting vertical referencing of this relative bathymetry to local datum. This second step began by determining extinction depth on relative bathymetry and the constants ( $\mathrm{m} 1$ and $\mathrm{m} 0$ ) used for vertical referencing to local datum. The determination of these constants was performed using Microsoft Excel (v. 2010, Microsoft Corporation).

$$
Z=87,868 x-73,281
$$

These constants ( $\mathrm{m} 1=87,868$ and $\mathrm{m} 0=73,281$ ) were introduced in Equation (5), in order to transform relative bathymetry into absolute bathymetry. The calibration process required information obtained from available in-situ water depth (Table 2).

\section{Results}

Automatic shoreline extraction and SDB methods applied to VHR images, as described in the current study, provided results with reliable intelligence, demonstrating the impact of natural phenomena in the studied area.

\subsection{Shoreline Variability}

The R2V method applied on satellite image acquired on 18 October 2014 and UAV orthomosaic image acquired on 28 May 2019 showed that for the period of 5 years, different areas of the pocket beach of San Vito Lo Capo have dramatically changed. This change was mainly observed on shoreline reference features observed (Figure 8) during the fieldwork conducted on 28 May 2019. We noticed that this coastal area is dominated by very fine sand (in the center), hard rocks forming the headland, and the harbor located in the western central part. The coastal erosion was noticed on the sand beach indicated by $15 \mathrm{~m}$ inland migration of the shoreline. The accretion process was observed in the harbor with 3 to $6 \mathrm{~m}$ offshore alternative migration of the shoreline (Figure 9).

Table 5 provides information on the changes occurred on the pocket beach of San Vito Lo Capo from 2014 to 2019. It showed an expansion length of $103 \mathrm{~m}$ for the sand beach shoreline and $10 \mathrm{~m}$ for beach distance. This might be explained by the migration of sand, from East to West, which was deposed in the harbor. For this period of 5 years, coastal erosion led to the submersion of $15 \mathrm{~m}$ distance inland with $17,446 \mathrm{~m}^{2}$ of sand beach eroded. However, a gain of $695 \mathrm{~m}^{2}$ of the sand was observed, especially in the harbor. These coastline changes indicated the vulnerability of coastal areas, even for the ones with headland believed to be their natural protection.

Table 5. Coastline changes on the pocket beach of San Vito Lo Capo from 2014 to 2019.

\begin{tabular}{|c|c|c|}
\hline Coastline Analysis Parameters & Situation in 2014 & Situation in 2019 \\
\hline Shoreline of the sand beach $(\mathrm{m})$ & 1776 & 1879 \\
\hline Distance of the beach $(\mathrm{m})$ & 1486 & 1496 \\
\hline Offshore distance of the pocket beach (m) & 936 & 951 \\
\hline Headland spacing (m) & 1772 & 1772 \\
\hline Total length of shoreline (m) & 3376 & 3451 \\
\hline Near shoreline eroded surface $\left(\mathrm{m}^{2}\right)$ & \multirow{2}{*}{\multicolumn{2}{|c|}{$\begin{array}{c}17,446 \\
695\end{array}$}} \\
\hline Near shoreline gained surface & & \\
\hline Sand beach surface $\left(\mathrm{m}^{2}\right)$ & 99,810 & 84,360 \\
\hline
\end{tabular}




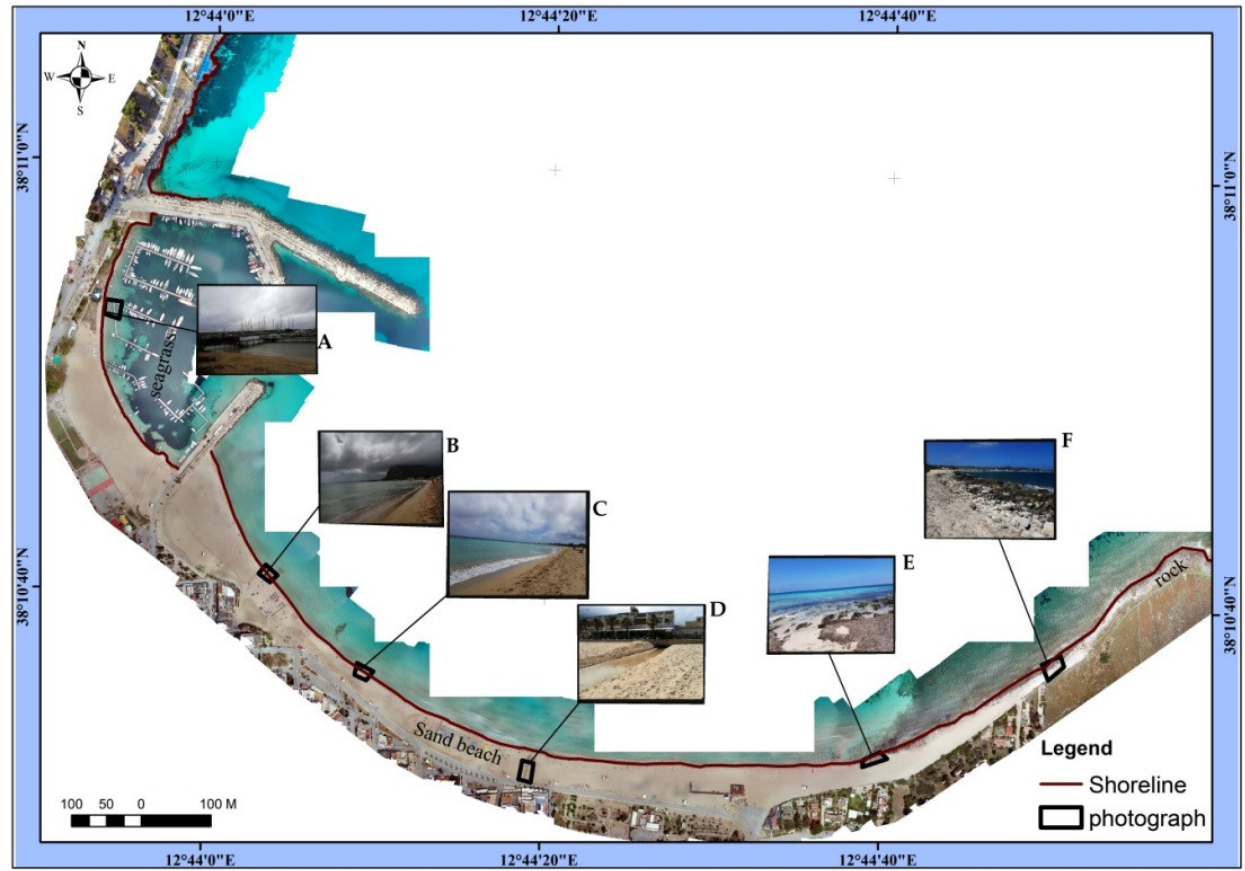

Figure 8. UAV orthomosaic image acquired on 28 May 2019 on the coast of San Vito Lo Capo with some photographs $(\mathrm{A}, \mathrm{B}, \mathrm{C}, \mathrm{D}, \mathrm{E}, \mathrm{F})$, indicating some shoreline reference features observed during the acquisition of very high-resolution UAV orthomosaic image. You can see, on these photographs taken on 28 May 2019, the shoreline occupied by dead seagrass (E), rocks (F), high and low water level (B,C), stream water flow (D), and the Harbor (A). The image also shows the position of coastline extracted on the orthomosaic on the coast of San Vito Lo Capo. Note the presence of seagrass (Posidonia Oceanica) in the harbor, and large sandy beach.

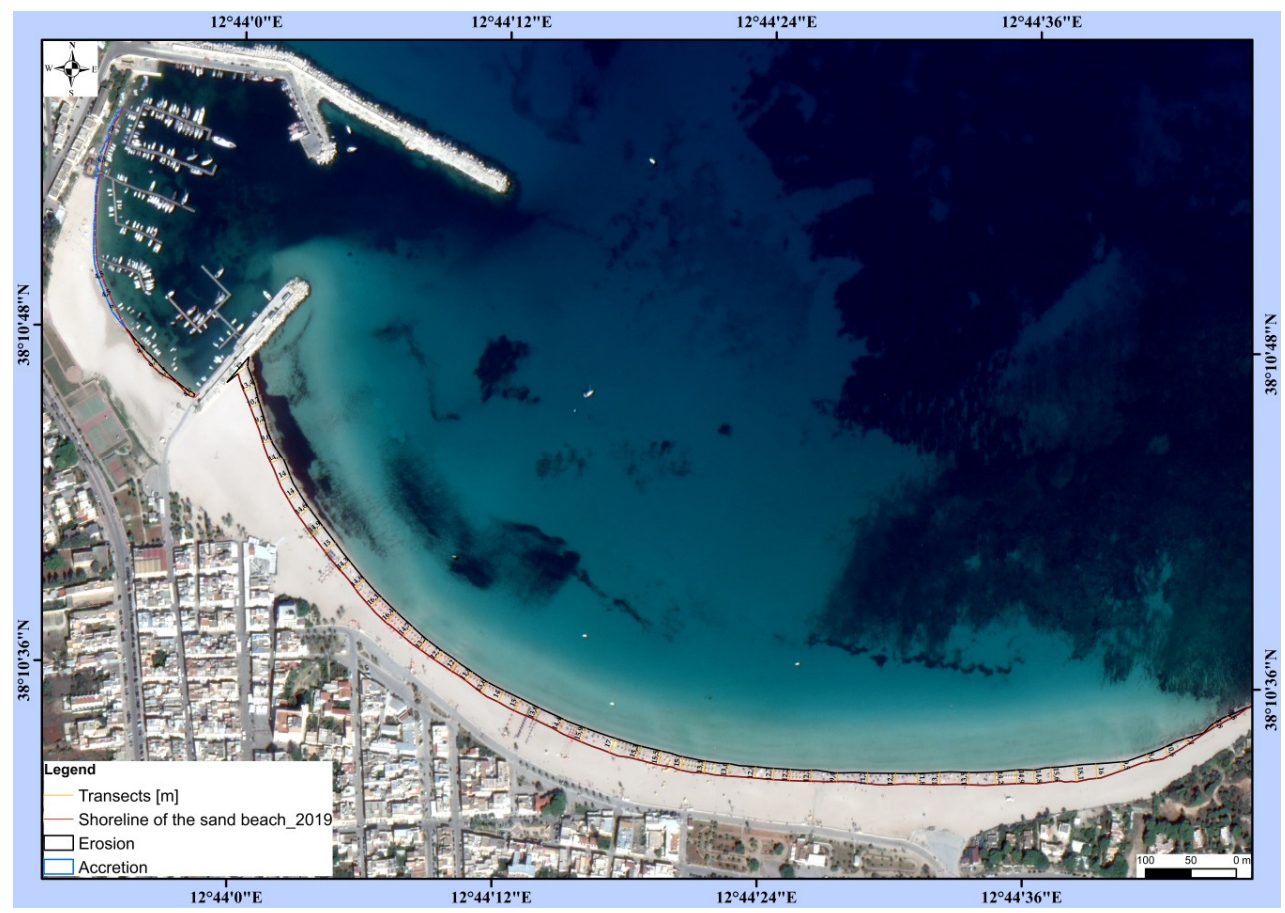

Figure 9. GeoEye-1 satellite image (2014) of the coast of San Vito Lo Capo with transects, indicating the migration of the shoreline occurred from 2014 to 2019. The shoreline positions were extracted on the UAV orthomosaic image (acquired on 28 May 2019) and GeoEye-1 satellite image (acquired on 18 October 2014). Note the coastal erosion on the sand beach and some accretion sediment in the harbor. 


\subsection{Satellite-derived Bathymetry}

The application of the log-band ratio method in a highly dynamic area of San Vito Lo Capo using blue and green spectral bands provided, in the first step, the relative bathymetry. This bathymetry was later calibrated and vertically referenced to the local datum using available in-situ data in order to obtain absolute bathymetry. Figure 10 shows SBD obtained from the GeoEye- 1 satellite image; we noticed the variation of water depth from $0 \mathrm{~m}$ to $9 \mathrm{~m}$ with high values observed in the northwestern part and low values near the shoreline of the sand beach. The western near-shoreline part showed relatively high values, suggesting the impact of the wind transporting sand from East to West as testified by the local population during our visit on 28 May 2019 to this area.

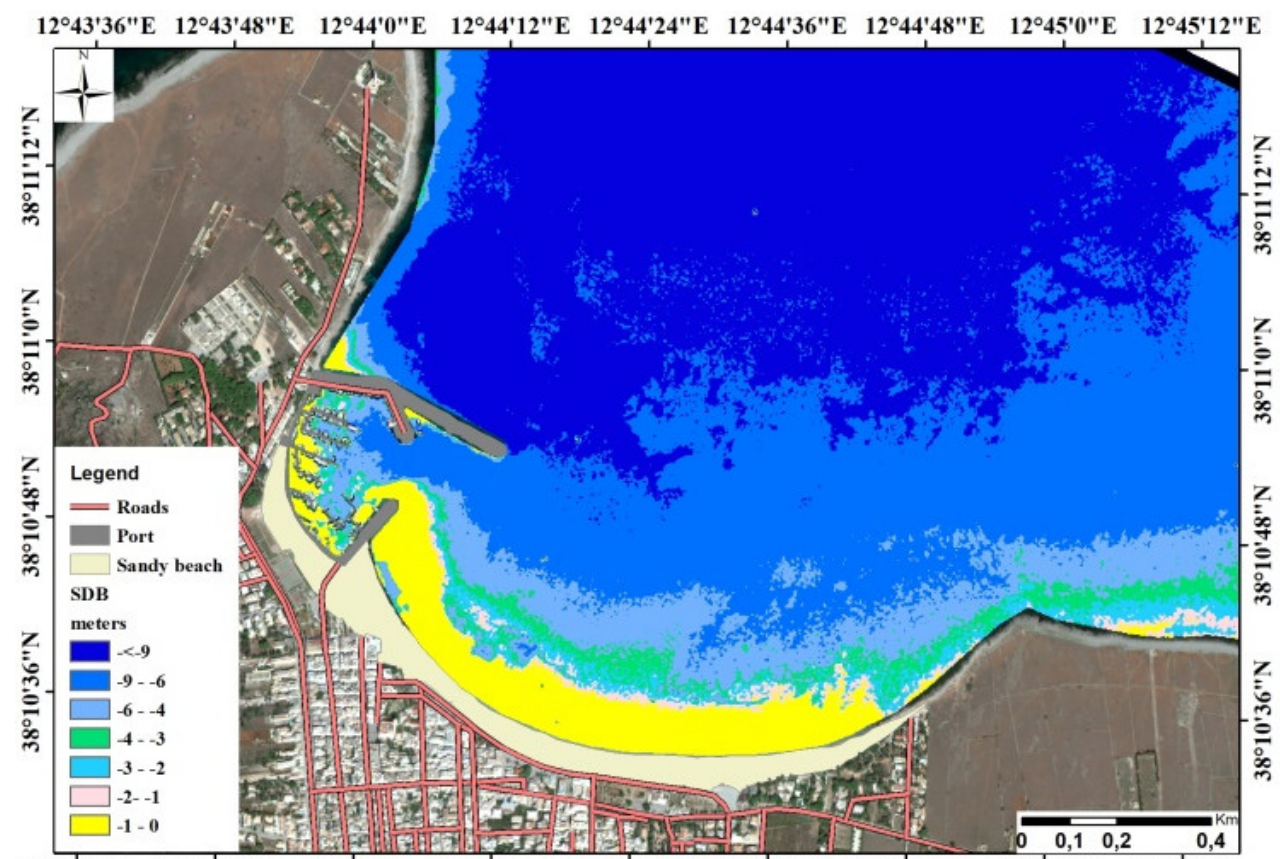

$12^{\circ} 43^{\prime} 36^{\prime \prime} \mathrm{E} \quad 12^{\circ} 43^{\prime} 48^{\prime \prime} \mathrm{E} \quad 12^{\circ} 44^{\prime} 0^{\prime \prime} \mathrm{E} \quad 12^{\circ} 44^{\prime} 12^{\prime \prime} \mathrm{E} \quad 12^{\circ} 44^{\prime} 24^{\prime \prime} \mathrm{E} \quad 12^{\circ} 44^{\prime} 36^{\prime \prime} \mathrm{E} \quad 12^{\circ} 44^{\prime} 48^{\prime \prime} \mathrm{E} \quad 12^{\circ} 45^{\prime} 0^{\prime \prime} \mathrm{E} \quad 12^{\circ} 45^{\prime} 12^{\prime \prime} \mathrm{E}$

Figure 10. SDB (satellite-derived bathymetry) extracted on the GeoEye-1 satellite image acquired on 18 October 2014 on the coast of San Vito Lo Capo.

In comparison with traditional method results obtained using SBES, Figure 11 shows that SDB provided additional information, especially in near-shore waters. In addition to water depth information, the use of satellite images provided information on the position of the shoreline, on the extent of sand beach, on the sand beach dynamics, as well as on built-up areas. These are useful information for scientists, hydrographers, and policymakers operating in coastal areas, especially in coastal management planning.

The comparison of SDB information with in-situ bathymetry showed a good relationship with a coefficient of determination $\mathrm{R}^{2}=0.7534$ (Figure 12). This high correlation between SBD and in-situ bathymetry demonstrated the ability of our SDB methodology to provide shallow water bathymetry, even in a highly dynamic environment.

Qualitative assessment of the results (Table 6) showed values for different depth ranges on which errors were calculated in function with available in-situ bathymetry in order to determine the overestimated and underestimated values on SDB. While some of these vertical uncertainties were in the range of maximum allowable total vertical uncertainty (TVU) values in ideal environmental conditions, the outrange ones might result in the presence of suspended sediments in this area. 


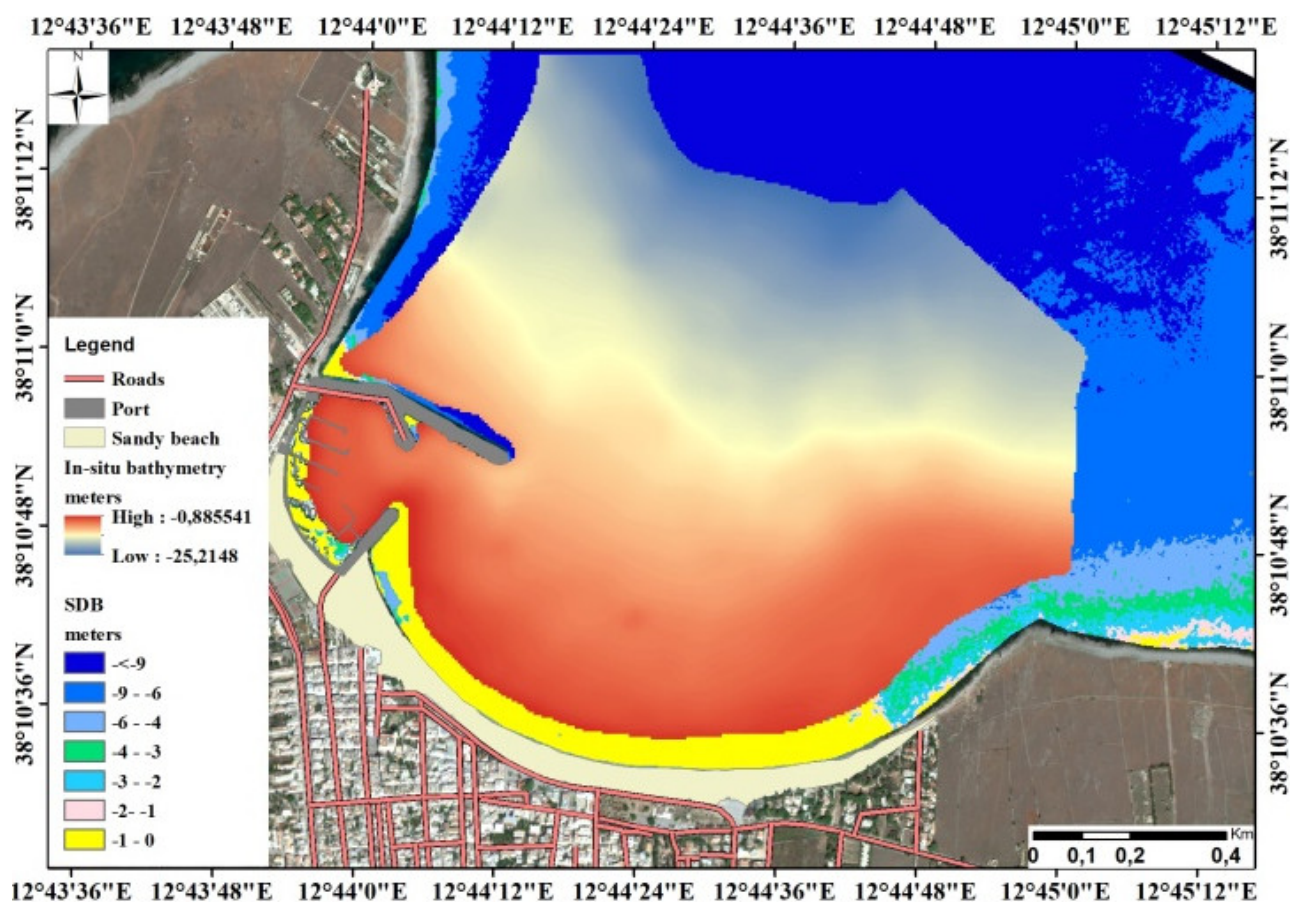

Figure 11. Spatial coverage comparison of SDB and SBES (single beam echo sounder) on the coast of San Vito Lo Capo.

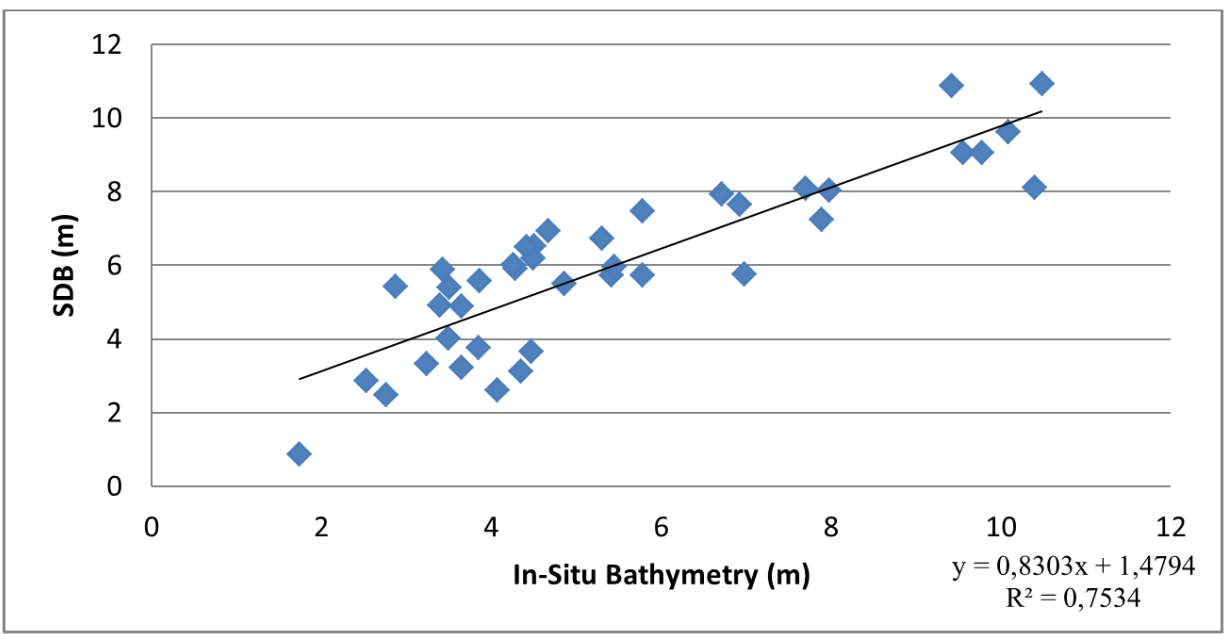

Figure 12. The relationship between SDB, obtained using log-band ratio method, and in-situ bathymetry acquired on the coast of San Vito Lo Capo.

Table 6. Quality assessment of satellite-derived bathymetry results.

\begin{tabular}{cc}
\hline Depth Range $(\mathbf{m})$ & Error $(\mathbf{m})$ \\
\hline $1-2$ & -0.85 \\
$2-3$ & 0.98 \\
$3-4$ & 1.01 \\
$4-5$ & 0.87 \\
$5-6$ & 0.79 \\
$6-7$ & 0.27 \\
$7-9$ & 0.02 \\
$9-10$ & -0.75 \\
\hline
\end{tabular}




\section{Discussion}

The current study explored the potential of very high spatial resolution images for shoreline and shallow water bathymetry mappings based on raster to vector (R2V) and log-band ratio methods, respectively. The presented methodology applied the R2V method for automatic shoreline extraction on GeoEye-1 satellite image and unmanned aerial vehicle (UAV) orthomosaic image, whereas the log-band ratio method was applied on GeoEye-1 satellite image for SDB. By analyzing spectral reflectance of water and non-water areas, very high resolution (VHR) images open up opportunities for applications once reserved for in-situ fieldworks. Based on threshold reflectance values of water and non-water pixels, we could extract the shoreline position on satellite, as well as on UAV images. Such shoreline position extracted on multi-temporal remote sensing data allows the assessment of the impact of the natural phenomenon occurring in coastal areas. In addition, based on the reflectance of water pixels, we demonstrated that water depth information could be extracted on the satellite image and calibrated with in-situ bathymetry, eventually allowing the mapping of shallow water bathymetry.

\subsection{Automatic Shoreline Extraction on GeoEye-1 Satellite and UAV Orthomosaic Images}

The results indicated that the coastal area of San Vito Lo Capo has distinct remotely sensed coastline features (Figure 8), useful for identification of the shoreline position on very high spatial resolution images acquired by satellite, as well as by UAV. Thus, the application of the R2V algorithm on binary images contributes to an automated shoreline mapping, a method much faster than traditional manually digitalization shoreline mapping. The ability to create a binary image from one single band (NIR or Red) and the availability of R2V in software, such as ENVI or ERDAS image, make the adopted mapping process a cost-effective tool, useful for monitoring shoreline position variability and eventually allowing coastal erosion impact assessment. Using the NIR band with $0.5 \mathrm{~m}$ spatial resolution and UAV orthomosaic image with $1.58 \mathrm{~cm}$ spatial resolution, the results obtained showed that from 2014 to 2019, the shoreline has migrated $15 \mathrm{~m}$ inland equals to approximately $17 \%$ loss of the sand beach. Such a level of detail is only achieved by analyzing very high spatial resolution images. While this mapping process provides accurate shoreline position due to the small size of a pixel of images used for the current study, it can also be adopted for the same studies conducted using freely-available open access moderate spatial resolution satellite images, such as Copernicus Sentinel-2 or Landsat 8 . This would enhance the same area revisit monitoring ( 5 to 3 days) and help identify the impact of sea-level rise affecting the low-lying areas. However, the integration of both very high and moderate spatial resolution images would largely improve spatial and temporal shoreline monitoring.

\subsection{Satellite-derived Bathymetry Mapping}

The log-band ratio method was applied to extract shallow water bathymetry from the GeoEye-1 satellite image in conjunction with in-situ bathymetry data. The log-band ratio method, an empirical satellite-derived bathymetry approach, allows the extraction of the depth of the seabed from water reflectance and training in-situ data. Initial preprocessing steps involve radiometric calibration and atmospheric correction, using the FLAASH algorithm, and water and non-water pixels distinction, based on threshold NIR reflectance values. The satellite image was acquired in good conditions, with a calm sea and 0 cloud cover, and thus, there was no need for sunlight correction or cloud masking.

The application of the log-band ratio requires two spectral bands-blue and green-which allow the mapping of relatively shallow water depth, and later empirically calibrated to local datum based on a minimum number of in-situ training data. This in-situ bathymetry is used in part for the estimation of empirical calibration parameters and for accuracy assessment. The applied method is based on the model developed by Stumpf et al. [41], which allows the determination of water depth with multispectral images acquired over areas with different bottom sea types. This is the case for the pocket beach of San Vito Lo Capo and many other Sicilian pocket beaches where the bottom sea is largely occupied by seagrasses, such as Posidonia oceanica, sand, or rocks. The bathymetry extracted 
in this area and regression analysis conducted for shallow water less than $11 \mathrm{~m}$ of the depth produced a good correlation between the extracted satellite-derived bathymetry and in-situ bathymetry with correlation coefficient $\mathrm{R}^{2}$ equals to 0.753 . Since the method is applicable for multispectral images with at least blue, green, and NIR bands, it could be more useful to conduct shallow water bathymetry using $10 \mathrm{~m}$ spatial resolution freely and open access Copernicus Sentinel-2 satellite image and an available limited number of in-situ bathymetry for regular shallow water monitoring as well as for shallow water bathymetry updating.

The methods presented in this paper allow: (i) to conduct coastal erosion assessment based on the automatically extracted shoreline. It is a cost-effective tool as the number of spectral bands used is limited in addition to the reduced time for the processing. (ii) To conduct shallow water monitoring and shallow water bathymetry updating in areas where traditional survey techniques using vessels and ships could not operate properly. Such monitoring can be improved by integrating freely-available and open-access satellite images combined with a limited number of in-situ bathymetry. (iii) To explore available tools and technologies, which can be used to fight the effect of climate change and help decision-makers adopt data-driven policies intended for coastal areas management.

\section{Conclusions}

The current study constituted the first coastal erosion assessment conducted on the coast of San Vito Lo Capo using VHR images. In order to obtain information on the current and past dynamic conditions of this coastal area, two VHR images were analyzed to automatically extract the shoreline position in 2014 and 2019, as well as the extraction of shallow water depth on satellite images acquired in 2014.

The R2V approach adopted allowed extracting automatically the position of shoreline with only one input band. This showed that intelligence on coastline dynamic situations could be obtained on a very limited volume of data and also with small computation capability, leading to more sustained coastal erosion monitoring. For the period of 5 years, we noticed that approximately 17\% of the sand beach was submerged, confirmed by $15 \mathrm{~m}$ inland shoreline migration, and $15,450 \mathrm{~m}^{2}$ of the sand beach was lost. On the other hand, SDB mapping demonstrated the application of satellite images in shallow water bathymetry studies. The Stumpf et al. equation applied on the GeoEye-1 satellite image in conjunction with available in-situ data provided useful water depth information for the first $9 \mathrm{~m}$. This depth was most challenging for the traditional bathymetry survey, and the methodology used could be adopted as a regular monitoring technique in vulnerable and rapidly evolving coastal areas.

Advances, both in algorithms and VHR images availability, improve the capability of monitoring vulnerable areas; we demonstrated that these images could be analyzed with simple methods, and obtain precision variable information in coastal areas. In addition, the ability to cover inaccessible, large, and high dynamic areas with very high spatial resolution images makes R2V and SDB technique alternative and cost-effective methods for bathymetric and coastal erosion studies.

Author Contributions: Conceptualization, A.M. and G.R.; methodology, A.M.; software, A.M., A.C., and G.B.; validation, G.R. and S.L.; formal analysis, A.M. and G.R.; investigation, A.M., A.C., F.G., A.M., G.B., and M.F.; resources, G.R.; data curation, A.M.; writing-original draft, A.M., G.R., and S.L.; writing-review and editing, A.M., G.R., and S.L.; visualization, M.C.; supervision, A.M. and S.L.; project administration, G.R.; funding acquisition, G.R. All authors have read and agreed to the published version of the manuscript.

Funding: G.R is supported by the European Regional Development Fund (INTERREG Italia-Malta) for the Project BESS: Pocket Beach Management and Remote Surveillance System.

Acknowledgments: This work was partially funded by the European Regional Development Fund (INTERREG Italia-Malta) under the Project BESS: Pocket Beach Management and Remote Surveillance System.

Conflicts of Interest: The authors declare no conflict of interest. The funders had no role in the design of the study; in the collection, analyses, or interpretation of data; in the writing of the manuscript, or in the decision to publish the results. 


\section{References}

1. Conti, L.A. Coastline changes near the "Maranhão-Ponta da Madeira" Port Complex, Brazil. J. Integ. Coast. Zone Manag. 2019, 19, 71-84. [CrossRef]

2. Braga, F.; Tosi, L.; Prati, C.; Alberotanza, L. Shoreline detection: Capability of COSMO-SkyMed and high-resolution multispectral images. Eur. J. Remote Sens. 2013, 46, 837-853. [CrossRef]

3. Maglione, P.; Parente, C.; Vallario, A. High Resolution Satellite Images to Reconstruct Recent Evolution of Domitian Coastline. Am. J. Appl. Sci. 2015, 12, 506-515. [CrossRef]

4. Rishikeshan, C.A.; Ramesh, H. A novel mathematical morphology based algorithm for shoreline extraction from satellite images. Geo-spat. inf. Sci. 2017, 20,345-352. [CrossRef]

5. Chen, B.; Yang, Y.; Xu, D.; Huang, E. A dual band algorithm for shallow water depth retrieval from high spatial resolution imagery with no ground truth. ISPRS J. Photo. Remote Sens. 2019, 151, 1-13. [CrossRef]

6. Hassler, S.C.; Baysal-Gurel, F. Unmanned Aircraft System (UAS) Technology and Applications in Agriculture. Agronomy 2019, 9, 618. [CrossRef]

7. Laporte-Fauret, Q.; Marieu, V.; Castelle, B.; Michalet, R.; Bujan, S.; Rosebery, D. Low-Cost UAV for High-Resolution and Large-Scale Coastal Dune Change Monitoring Using Photogrammetry. J. Mar. Sci. Eng. 2019, 7, 63. [CrossRef]

8. Agrafiotis, P.; Skarlatos, D.; Georgopoulos, A.; Karantzalos, K. Shallow water bathymetry mapping from UAV imagery based on machine learning. arXiv 2019, arXiv:1902.10733. [CrossRef]

9. Pellicani, R.; Argentiero, I.; Manzari, P.; Spilotro, G.; Marzo, C.; Ermini, R.; Apollonio, C. UAV and Airborne LiDAR Data for Interpreting Kinematic Evolution of Landslide Movements: The Case Study of the Montescaglioso Landslide (Southern Italy). Geosciences 2019, 9, 248. [CrossRef]

10. Reimann, L.; Vafeidis, A.T.; Brown, S.; Hinkel, J.; Tol, R.S.J. Mediterranean UNESCO World Heritage at risk from coastal flooding and erosion due to sea-level rise. Nat. Commun. 2018, 9, 4161. [CrossRef] [PubMed]

11. Nikolakopoulos, K.; Kyriou, A.; Koukouvelas, I.; Zygouri, V.; Apostolopoulos, D. Combination of Aerial, Satellite, and UAV Photogrammetry for Mapping the Diachronic Coastline Evolution: The Case of Lefkada Island. ISPRS Int. J. Geo-Inf. 2019, 8, 489. [CrossRef]

12. Klemas, V. The role of remote sensing in predicting and determining coastal storm impacts. J. Coast. Res. 2009, 6, 1264-1275. [CrossRef]

13. Sudmanns, M.; Tiede, D.; Lang, S.; Bergstedt, H.; Trost, G.; Augustin, H.; Baraldi, A.; Blaschke, T. Big Earth data: Disruptive changes in Earth observation data management and analysis? Int. J. Digit. Earth 2019, 1-19. [CrossRef]

14. Lou, X.; Huang, W.; Shi, A.; Teng, J. Raster to vector conversion of classified remote sensing image. In Proceedings of the 2005 IEEE International Geoscience and Remote Sensing Symposium IGARSS-05, Seoul, Korea, 29 July 2005; Volume 5, pp. 3656-3658.

15. Guariglia, A.; Buonamassa, A.; Losurdo, A.; Saladino, R.; Trivigno, M.L.; Zaccagnino, A.; Colangelo, A. A Multisource Approach for Coastline Mapping and Identification of Shoreline Changes. Ann. Geophys. 2006, 41, 295-304.

16. Gesch, D.; Wilson, R. Development of a seamless multisource topographic/bathymetric elevation model of Tampa Bay. Mar. Technol. Soc. J. 2002, 35, 58-64. [CrossRef]

17. Monteys, X.; Harris, P.; Caloca, S.; Cahalane, C. Spatial Prediction of Coastal Bathymetry Based on Multispectral Satellite Imagery and Multibeam Data. Remote Sens. 2015, 7, 13782-13806. [CrossRef]

18. Muzirafuti, A.; Barreca, G.; Crupi, A.; Faina, G.; Paltrinieri, D.; Lanza, S.; Randazzo, G. The Contribution of Multispectral Satellite Image to Shallow Water Bathymetry Mapping on the Coast of Misano Adriatico, Italy. J. Mar. Sci. Eng. 2020, 8, 126. [CrossRef]

19. Seif, A.K.; Kuroiwa, M.; Abualtayef, M.; Mase, H.; Matsubara, Y. A hydrodynamic model of nearshore waves and wave-induced currents. Inter. J. Nav. Archit. Oc. Engng. 2011, 3, 216-224. [CrossRef]

20. Clementi, E.; Oddo, P.; Drudi, M.; Pinardi, N.; Korres, G.; Grandi, A. Coupling hydrodynamic and wave models: First step and sensitivity experiments in the Mediterranean Sea. Ocean Dynam. 2017, 67, 1293-1312. [CrossRef] 
21. Van Rijn, L.C. Coastal erosion and control. Ocean Coast. Manag. 2011, 54, 867-887. [CrossRef]

22. Guzinski, R.; Spondylis, E.; Michalis, M.; Tusa, S.; Brancato, G.; Minno, L.; Hansen, L.B. Exploring the Utility of Bathymetry Maps Derived with Multispectral Satellite Observations in the Field of Underwater Archaeology. Open Archaeol. 2016, 2, 243-263. [CrossRef]

23. Bannari, A.; Kadhem, G. MBES-CARIS Data Validation for Bathymetric Mapping of Shallow Water in the Kingdom of Bahrain on the Arabian Gulf. Remote Sens. 2017, 9, 385. [CrossRef]

24. Anderson, J.T.; Van Holliday, D.; Kloser, R.; Reid, D.G.; Simard, Y. Acoustic seabed classification: Current practice and future directions. ICES J. Mar. Sci. 2008, 65, 1004-1011. [CrossRef]

25. Zhao, J.; Zhao, X.; Zhang, H.; Zhou, F. Shallow Water Measurements Using a Single Green Laser Corrected by Building a Near Water Surface Penetration Model. Remote Sens. 2017, 9, 426. [CrossRef]

26. Wang, C.K.; Philpot, W.D. Using airborne bathymetric Lidar to detect bottom type variation in shallow waters. Remote Sens. Environ. 2007, 106, 123-135. [CrossRef]

27. Conner, J.T.; Tonina, D. Effect of cross-section interpolated bathymetry on 2D hydrodynamic results in a large river. Earth Surf. Process. Landf. 2014, 39, 463-475. [CrossRef]

28. Horritt, M.S.; Bates, P.D.; Mattinson, M.J. Effects of mesh resolution and topographic representation in 2D finite volume models of shallow water fluvial flow. J. Hydrol. 2006, 329, 306-314. [CrossRef]

29. Chénier, R.; Faucher, M.-A.; Ahola, R. Satellite-Derived Bathymetry for Improving Canadian Hydrographic Service Charts. ISPRS Int. J. Geo-Inf. 2018, 7, 306. [CrossRef]

30. Polcyn, F.C.; Brown, W.L.; Sattinger, I.J. The Measurement of Water Depth by Remote Sensing Techniques; Report No. 8973-26-F.; Willow Run Laboratories of the Institute of Science and Technology, The University of Michigan: Ann Arbor, MI, USA, 1970.

31. Siermann, J.; Harvey, C.; Morgan, G.; Heege, T. Satellite derived bathymetry and digital elevation models (DEM). In Proceedings of the International petroleum technology conference, Doha, Qatar, 19-22 January 2014.

32. EOMAP. “Satellite-Derived Bathymetry". Available online: https://www.eomap.com/services/bathymetry/ (accessed on 1 September 2019).

33. TCARTA. "What is Satellite Derived Bathymetry?". Available online: https://www.tcarta.com/blog/what-issatellite-derived-bathymetry/ (accessed on 1 September 2019).

34. Mavraeidopoulos, A.K.; Pallikaris, A.; Oikonomou, E. Satellite Derived Bathymetry (SDB) and Safety of Navigation. Int. Hydrogr. Rev. 2017, 17, 7-19.

35. Basterretxea, G.; Orfica, A.; Jordi, A.; Casas, B.; Lynett, P.; Liu, P.L.F.; Duarte, C.M.; Tintore, J. Seasonal dynamics of a microtidal pocket beach with Posidonia oceanica seabed (Mallorca, Spain). J. Coast. Res. 2004, 20, 1155-1164. [CrossRef]

36. Schwab, W.C.; Thieler, R.E.; Allen, J.R.; Foster, D.S.; Ann Swift, B.; Denny, J.F. Influence of inner-continental shelf geologic framework on the evolution and behaviour of the barrier-island system between Fire Island Inlet and Shinnecock Inlet, Long Island, New York. J. Coast. Res. 2000, 16, 408-422.

37. Aguzzi, M.; Bonsignore, F.; De Nunzio, N.; Morelli, M.; Paccagnella, T.; Romagnoli, C.; Unguendoli, S. Stato del Litorale Emiliano-Romagnolo al 2012: Erosione e Interventi di Difesa; Agenzia Prevenzione Ambiente Energia Emilia-Romagna: Bologna, Italy, 2016; ISBN 978-88-87854-41-1.

38. Muzirafuti, A.; Crupi, A.; Lanza, S.; Barreca, G.; Randazzo, G. Shallow water bathymetry by satellite image: A case study on the coast of San Lo Capo Peninsula, Northwestern Sicily, Italy. In Proceedings of the 2019 IMEKO TC-19 International Workshop on Metrology for the Sea, Genova, Italy, 3-5 October 2019.

39. IOCCG. Atmospheric Correction for Remotely-Sensed Ocean-Colour Products. In Reports of the International Ocean-Colour Coordinating Group (IOCCG); No. 10; Wang, M., Ed.; International Ocean-Colour Coordinating Group: Dartmouth, NS, Canada, 2010.

40. Eugenio, F.; Marcello, J.; Martin, J.; Rodríguez-Esparragón, D. Benthic Habitat Mapping Using Multispectral High-Resolution Imagery: Evaluation of Shallow Water Atmospheric Correction Techniques. Sensors 2017, 17, 2639. [CrossRef] [PubMed] 
41. Stumpf, R.P.; Holderied, K.; Sinclair, M. Determination of water depth with high-resolution satellite imagery over variable bottom types. Limnol. Oceanogr. 2003, 48, 547-556. [CrossRef]

42. Eugenio, F.; Marcello, J.; Martin, J. High-resolution maps of bathymetry and benthic habitats in shallow-water environments using multispectral remote sensing imagery. IEEE Trans. Geosci. Remote Sens. 2015, 53, 3539-3549. [CrossRef] 